\title{
Prevalence and intensity of Trichuris trichiura infection and associated determinants in rural tea garden areas of sylhet, Bangladesh
}

\begin{abstract}
The current study of the prevalence, intensity and associated determinants of Trichuris trichiura infection was carried out from June' 2014 to May' 2015 among five tea gardens of Sylhet Sadar Upazila of Sylhet district, Bangladesh. Out of 300 participants $42(14.00 \%)$; $95 \%$ CI 10.28-18.45) were found robustly infected with T. trichiura of the age groups 11-20 years age group showed highest prevalence $31.58 \%(95 \%$ CI $12.58-56.55)$ than other age groups. Multivariate analysis identified season $(\mathrm{OR}=6.15 ; 95 \%$ CI $2.27-16.66, \mathrm{P}=0.01)$, areas, periodic anthelmintic does not taking, unhygienic disposal of the stool $(\mathrm{OR}=2.79$, $95 \% \mathrm{CI} 1.44-5.43, \mathrm{P}=0.02)$ are as the potential determinants contributing to the intensity of $T$. trichiura infection. Low income of the family significantly (OR=2.15; $95 \%$ CI 1.11 4.15, $\mathrm{P}=0.02$ ) associated with $T$. trichiura infection. Low level of education of the parents associated with moderate intensity of $T$. trichiura infection. Therefore deworming of the tea garden children and worker are warranted. Preventive measures should be emphasized on important determinants like regular taking of anthelmintics, proper disposal of children's stool, appropriate water management and children should be avoided entering to household dirt.
\end{abstract}

Keywords: prevalence, trichuris trichiura, intensity, determinants, tea garden community
Volume 6 Issue 2 - 2018

\section{Muhammed Hossain, Jamal Uddin Bhuiyan Department of Parasitology, Sylhet Agricultural University, Bangladesh}

Correspondence: Muhammed Hossain, Department of Parasitology, Faculty of Veterinary, Animal and Biomedical Science, Sylhet Agricultural University, Sylhet-3100, Bangladesh, Email bmhossain34sau@gmail.com

Received: February 28, 2018 | Published: April 10, 2018

\section{Introduction}

The intestinal parasitic infection particularly $T$. trichiura causes hundreds of thousands of deaths every year. ${ }^{1}$ It has been recorded that over one billion people are infected with Ascaris lumbricoides, 800 million with hookworm and 770 million with $T$. trichiura. ${ }^{2}$ Trichuriasis prevalent throughout the tropical areas especially the areas associated with the conditions of poverty, unsafe water, sanitation and hygiene particularly in developing nations..$^{3-5}$ Previous studies have shown the main risk factors for helminths infection are rural residency, low economic status and poor knowledge on hygiene. ${ }^{6,7}$ There are few data on the epidemiology of helminths infection in tea garden community of Sylhet ${ }^{8}$ but no data available on risk factors of helminths infections. Negative effects of trichuriases infection include diminished physical fitness, growth retardation, delayed intellectual development and cognition. ${ }^{6,9}$ To investigate the epidemiology of helminths infection in tea garden children and workers we analyzed collected data during the study period in tropical Sylhet. Current stratagem for controlling helminths infections are primarily based on periodic anthelmintic treatment of community people, and secondarily on education and sanitation improvement. The use of pit latrines and improved drinking water has been associated with reduction of prevalence of helminths infections..$^{10}$ Treatment based control strategies goal to control rate of mortality through reductions of transmission of helminths infection in the community. ${ }^{11}$ An understanding of the determinants of infections would assist in designing the most appropriate control measures. The aim of the present study was to determine robustly the prevalence and determinants and clinical features associated with trichuriases infection in tea garden community.

\section{Materials and methods}

\section{Study area}

The tea garden areas of Sylhet district located $315 \mathrm{~km}$ north east from capital city Dhaka were selected for this study as it is the poorest area of Bangladesh. Sylhet is located at $24.8917^{\circ} \mathrm{N}$ and $91.8833^{\circ} \mathrm{E}$. It has 86074 units of house hold and total area $323.17 \mathrm{~km}^{2} .^{12}$ More than $75 \%$ rainfall occurs in the monsoon period. Average temperature of the country ranges from 17 to $20.60^{\circ} \mathrm{C}$ during winter and 26.90 to $31.10^{\circ} \mathrm{C}$ during summer. Average relative humidity for the whole year ranges from $70.50 \%$ to $78.10 \%$ in Bangladesh. ${ }^{13}$ This district is occupied by high proportion of ethnic minorities, stingy household condition, poor road condition, no prohibition for preventive and curative measures (Figure 1).

\section{Duration of the study}

The study was conducted for a period of 12 months starting from June' 2014 to May' 2015.

\section{Ethical approval}

The study was approved by the Ethical Committee for public health research, Sylhet Agricultural University, Sylhet-3100. Verbal consent was obtained from the parents or legal caretakers of the children. Children positive with intestinal parasites were treated with appropriate drugs by physicians from Upazila Hospitals free of cost. 


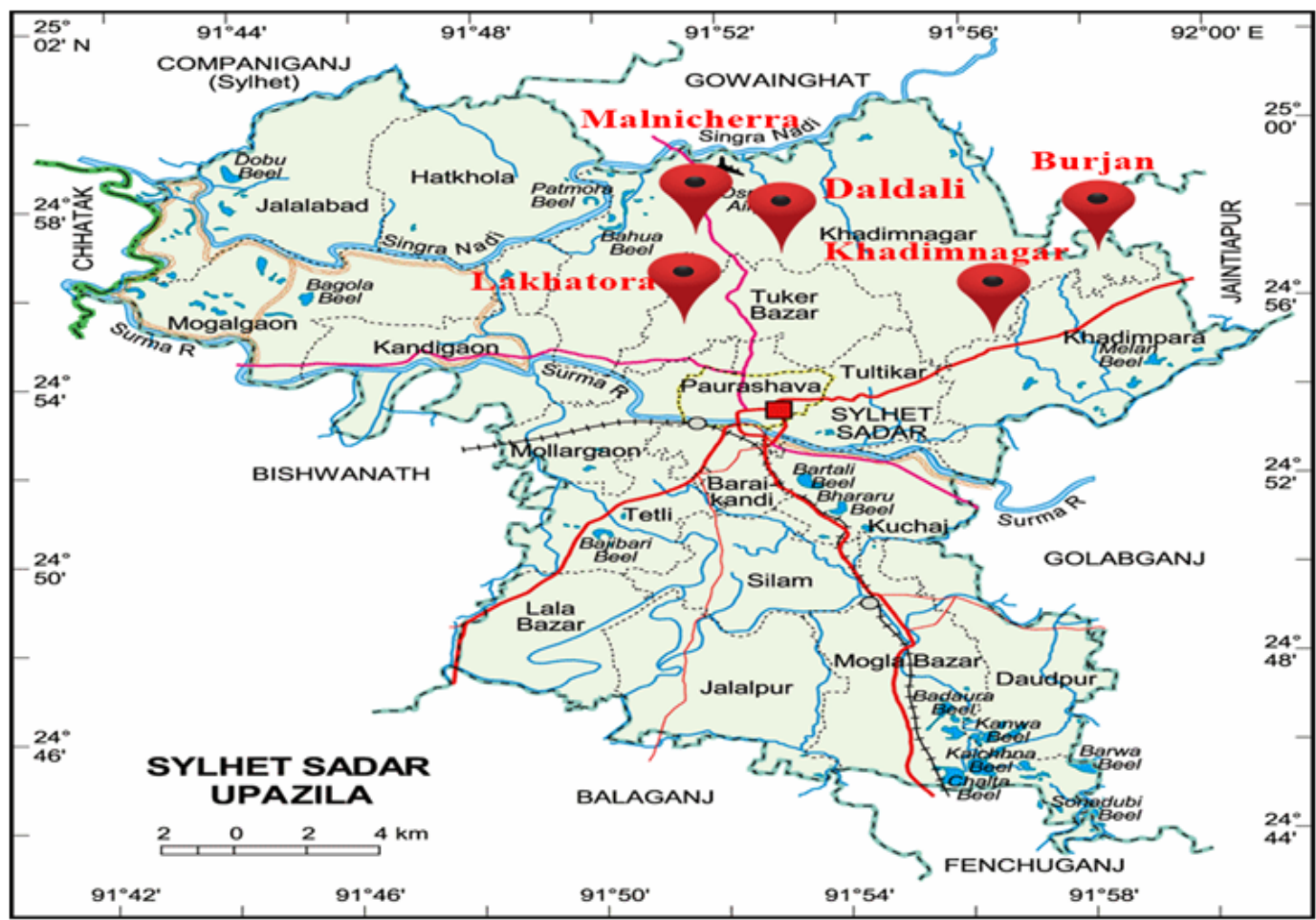

Figure I Location of tea garden in Sylhet Sadar Upazilla

\section{Data collection}

Demographic and socio-economic information of the participant and other member of the family were collected using standard questionnaire. The probable potential determinants like age, sex, participants schooling, Parent's occupation, taking anthelmintic, type of latrine, toilet floor, how often toilet clean, washing hand and feet coming from toilet, access to safe drinking water, and work in bare foot. The parents were also asked for if any ill health condition last six month as itching, abdominal pain, diarrhea, weight loss, fatigue and weakness, and blood in stool etc. Household socio-economic status like monthly income of family, education of the house head, household floor, ownership of the animal cattle, sheep, goat, dog, cat and pigs.

\section{Sample collection}

Labeled stool containers were provided to the parents of each child. The filled containers were collected in the following morning and were carried in a cool ice-box to the Laboratory and examination was performed within 24 hour of collection.

\section{Study design and selection of the tea garden}

In first step, the heads of respective tea garden from all five tea garden were asked for community outreach activities in June' 2014 to prepare a list of all primary schools in their respective tea garden including the number of children attending grades 2 and 3. All interested participants of the selected household were also enlisted for the study with making proper consent of the household head.

\section{Analysis of collected stool sample}

\section{Direct smear method and Kato Katz Techniques}

The collected stool samples were examined by direct saline smear for the presence of parasitic ova and the same sample also were subjected to Kato Katz thick smear ${ }^{14}$ and in every slide egg of each parasite species evaluated and recorded (Figure 2). The intensity of infection [egg per gram (EPG)] was determined. Based on the criteria of the [15]: A. lumbricoides: light, 0-4999 EPG; moderate, 500049999 EPG; and heavy, $\geq 50000$ EPG; T. trichiura: light, 0-999 EPG; moderate, 1000-9999 EPG; and heavy, $\geq 10000$ EPG; and hookworm: light, 0-399 EPG; moderate, 400-2999 EPG; and heavy, $\geq 3000$ EPG.

\section{Data analysis}

Statistical analysis was performed by Logistic Regression procedure using STATA 13 (College Station, Texas 77845 USA) and the level of significance was considered as $\mathrm{P}<0.05$. In the univariable analysis, $\lambda^{2}$ test done for determinants associated with infection. In the multivariable logistic regressions, variables with a P-value of $\leq 0.20$ in the univariable analysis were included as predictors. ORs and 95\% CI were reported. P-values $<0.05$ were regarded as significant.

\section{Results}

\section{Household, education and income of the family}

Of the participants $91.67 \%$ live in the house floor made up of mud, $08.00 \%$ concrete made and $0.33 \%$ in semi cemented floor house. In the tea garden community $34.67 \%$ had primary education, $05.33 \%$ 
secondary education and $60 \%$ Illiterate. The participant's father possesses higher literacy than mother. Primary education $28.67 \%$ and $21.00 \%$; Secondary $24.00 \%$ and $01.00 \%$; Illiteracy $47.33 \%$ and
$78.00 \%$ respectively for male and female (Table 1). Occupation and family income of the participants playing a crucial role in trichuris infection (Table 2) (Table 3).
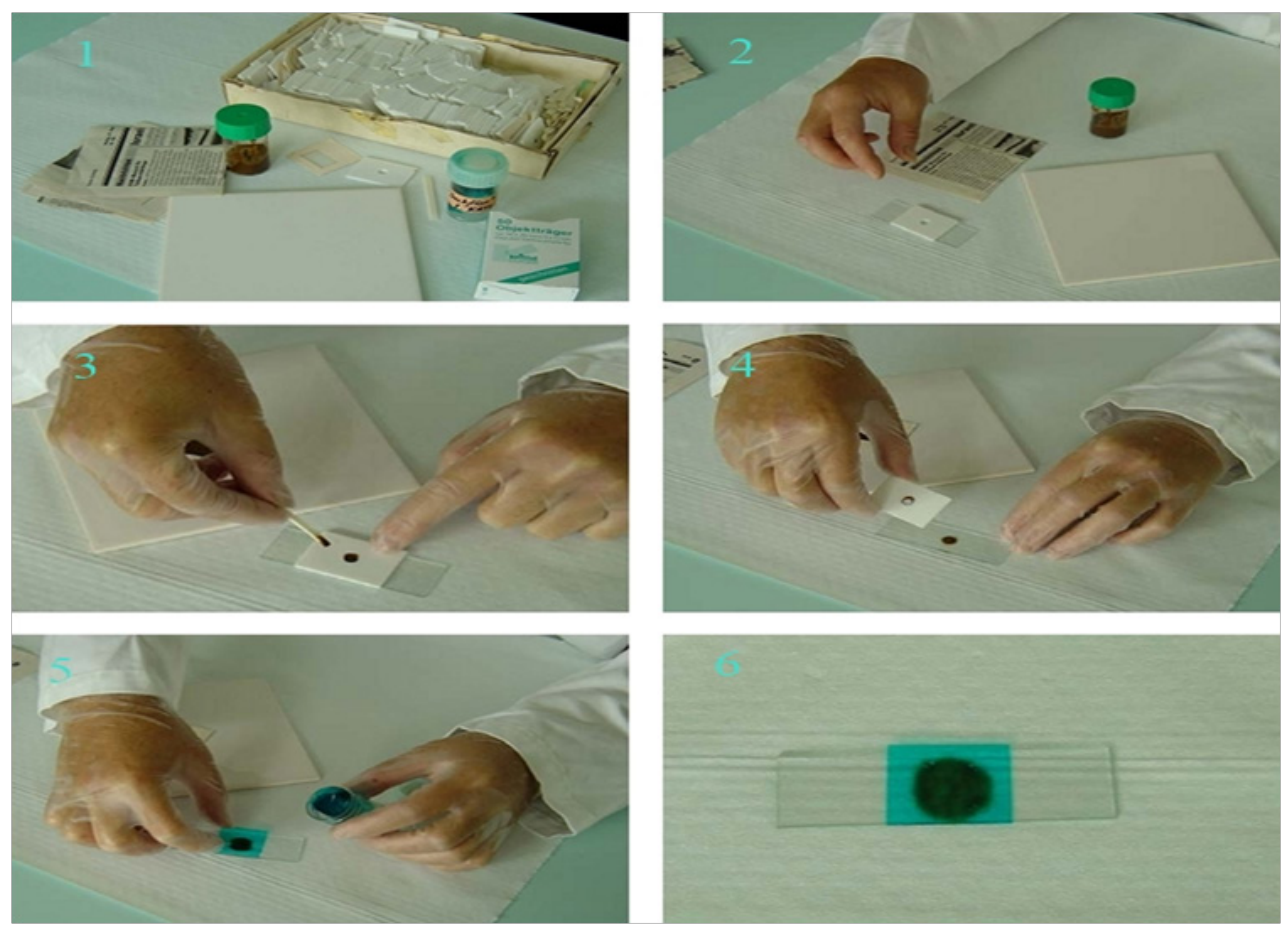

Figure 2 Preparation of Kato Katz slides (Step I:All the required tools are accommodated; Step 2: Setting up the slide and plastic strip with pit; Step 3 : Placement of required quantity of stool in the pit; Step 4: Removal of the plastic strip and desired amount of stool remained in the glass slide; Step 5: Placing the nylon screen over the stool sample; Step 6: Slide prepared and ready for ova counting under microscope).

Table I Educational status of the 300 participants and their parents in tea garden community

\begin{tabular}{|c|c|c|}
\hline Characteristics & Frequency & Percentage \\
\hline \multicolumn{3}{|c|}{ Participants schooling } \\
\hline Primary & 104 & 34.67 \\
\hline Secondary & 16 & 5.33 \\
\hline No schooling & 180 & 60 \\
\hline \multicolumn{3}{|c|}{ Mother's schooling } \\
\hline Primary & 63 & 21 \\
\hline Secondary & 3 & I \\
\hline No schooling & 234 & 78 \\
\hline \multicolumn{3}{|c|}{ Father's schooling } \\
\hline Primary & 86 & 28.67 \\
\hline Secondary & 72 & 24 \\
\hline No schooling & 142 & 47.33 \\
\hline
\end{tabular}

Table 2 Occupational status of the parents of 300 participants in tea garden community

\begin{tabular}{lll}
\hline Level of occupation & Frequency & Percentage \\
\hline Father's occupation & & 3.67 \\
Unemployed & 11 & 60.67 \\
Day labourer & 182 & 26.67 \\
Service & 80 & 3 \\
Tea garden worker & 9 & 6 \\
Business & 18 & \\
Mother's occupation & & 53.33 \\
Housewife & 167 & 0.33 \\
Service & 1 & 44 \\
Business & 132 & \\
\hline
\end{tabular}


Table 3 Other demographic information of the 300 participants of tea garden community

\begin{tabular}{|c|c|c|}
\hline $\begin{array}{l}\text { Other demographic } \\
\text { information }\end{array}$ & Frequency & Percentage \\
\hline \multicolumn{3}{|l|}{ Age group } \\
\hline$\leq 10$ & 242 & 80.67 \\
\hline 20-Nov & 19 & 6.33 \\
\hline $21-30$ & 13 & 4.33 \\
\hline $31-40$ & 12 & 4 \\
\hline 4I-up & 14 & 4.67 \\
\hline \multicolumn{3}{|l|}{ Sex } \\
\hline Male & 177 & 59 \\
\hline Female & 123 & 41 \\
\hline \multicolumn{3}{|l|}{ Name of the areas } \\
\hline Khadim tea estate & 47 & 15.67 \\
\hline Burjan tea estate & 79 & 26.33 \\
\hline Lakkatora tea estate & 65 & 21 \\
\hline Malnichara tea esstate & 63 & 21.67 \\
\hline Daldali tea estate & 46 & 15.33 \\
\hline \multicolumn{3}{|c|}{ Category of weight (kg) } \\
\hline$\leq 20$ & 186 & 62 \\
\hline $21-40$ & 65 & 21.67 \\
\hline 4I-up & 49 & 16.33 \\
\hline \multicolumn{3}{|c|}{ Income of house (Taka) } \\
\hline$\leq 5000$ & 103 & 34.33 \\
\hline$>5000$ & 197 & 65.67 \\
\hline \multicolumn{3}{|c|}{ No of people living in house } \\
\hline$\leq 4$ & 145 & 48.33 \\
\hline$\geq 5$ & 155 & 51.67 \\
\hline \multicolumn{3}{|l|}{ Name of the season } \\
\hline Rainy & 65 & 21.67 \\
\hline Winter & 116 & 38.67 \\
\hline Summer & 119 & 39.67 \\
\hline
\end{tabular}

\section{Demographic information (Table 4)}

\section{Prevalence of Trichuris infection}

The T. trichiura organism has been identified from stool specimens with the overall prevalence $14.00 \%$ (95\% CI 10.28-18.45). The prevalence of trichuriases is higher in male $14.69 \%$ (95\% CI $09.83-$ 20.78) than female $13.01 \%$ (95\% CI 07.62-20.26). Highest infection occurred during Rainy season and which is $24.62 \%$ (95\% CI 14.77 36.87 ) then the infection gradually decreases from $17.24 \%(95 \% \mathrm{CI}$ $10.86-25.36)$ to $05.04 \%$ (95\% CI $01.87-10.65)$ respectively for Winter and Summer. The highest infection recorded in the age group 11-20 years $31.58 \%$ (95\% CI 12.58-56.55) and lowest infection in $\geq 41$ age groups $07.14 \%$ (95\% CI 0.18-33.87) (Table 4). Interesting finding of our work was no T. trichiura infection in Daldali tea garden, it is most likely because of the geographical and hygienic condition of this area. People of this area are quietly abided by the hygienic health regulations rules.

Table 4 Prevalence of Trichuris trichiura infection in tea garden community of Sylhet

\begin{tabular}{|c|c|c|c|}
\hline Points & $\begin{array}{l}\text { Total no. of } \\
\text { tested }\end{array}$ & $\begin{array}{l}\text { Total no. } \\
\text { of positive }\end{array}$ & $\begin{array}{l}\text { Prevalence ( } 95 \% \\
\text { confidence Intervals) }\end{array}$ \\
\hline \multicolumn{4}{|l|}{ Season } \\
\hline Rainy & 65 & 16 & $24.62 \%(14.77-36.87)$ \\
\hline Winter & 116 & 20 & $17.24 \%(10.86-25.36)$ \\
\hline Summer & 119 & 6 & $05.04 \%(01.87-10.65)$ \\
\hline \multicolumn{4}{|l|}{ Age } \\
\hline$\leq 10$ & 242 & 30 & $12.39 \%(08.52-17.22)$ \\
\hline 20-Nov & 19 & 6 & $31.58 \%(12.58-56.55)$ \\
\hline $21-30$ & 13 & 3 & $23.08 \%(05.04-53.8 I)$ \\
\hline $31-40$ & 12 & 2 & $16.67 \%(02.09-48.4 I)$ \\
\hline$\geq 41$ & 14 & 1 & $07.14 \%(0.18-33.87)$ \\
\hline \multicolumn{4}{|l|}{ Areas } \\
\hline $\begin{array}{l}\text { Khadim tea } \\
\text { estate }\end{array}$ & 47 & 14 & $29.79 \%(I 7.34-44.90)$ \\
\hline $\begin{array}{l}\text { Burjan tea } \\
\text { estate }\end{array}$ & 79 & 18 & $22.78 \%(14.10-33.60)$ \\
\hline $\begin{array}{l}\text { Lakkatora tea } \\
\text { estate }\end{array}$ & 65 & 2 & $03.08 \%(00.38-10.68)$ \\
\hline $\begin{array}{l}\text { Malnichara tea } \\
\text { estate }\end{array}$ & 63 & 8 & $12.70 \%(05.65-23.50)$ \\
\hline $\begin{array}{l}\text { Daldali tea } \\
\text { estate }\end{array}$ & 46 & - & \\
\hline \multicolumn{4}{|l|}{ Sex } \\
\hline Male & 177 & 26 & $14.69 \%(09.83-20.78)$ \\
\hline Female & 123 & 16 & $13.01 \%(07.62-20.26)$ \\
\hline
\end{tabular}

Intensity of T. trichiura infection in tea garden community of Sylhet (Table 5)

\section{Determinants for T. trichiura infection}

The univariable analysis disclosed season, areas, participant's schooling, receiving anthelmintic periodically, family income and disposal of the stool were significantly $\mathrm{P}<0.05$ associated with Trichuris infection (Table 6). The rural slum of the tea garden poorly arranged and the unhygienic condition of the areas favor the transmission cycle of the infection.

The multivariable logistic regression shows that season are keenly associated with $T$. trichiura infection and the Rainy season revealed $\mathrm{OR}=6.15(95 \%$ CI $2.27-16.66)$ than the Winter $\mathrm{OR}=3.92(95 \% \mathrm{CI}$ 1.51-10.17). Periodic anthelmintic taking reduces the chance of infection than those are not taking anthelmintics $\mathrm{OR}=2.07(95 \% \mathrm{CI}$ 1.07-4.01). The tea garden location also favors the transmission cycle of $T$. trichiura due to poor hygiene maintenance in the rural slums (Table 7). 
Table 5 Intensity of T. trichiura infection in tea garden community of Sylhet

\begin{tabular}{ll}
\hline Trichuris trichiura & Percentage of infection \\
\hline No infection & $258(86.00)$ \\
Light & $30(10.00)$ \\
Moderate & $08(02.67)$ \\
Heavy & $04(01.33)$ \\
Total & $300(100.0)$
\end{tabular}

The epg (egg per gram) counting by Kato Katz revealed light, moderate and heavy infection of T. trichiura and which were $10.00 \%, 02.67 \%$ and $01.33 \%$ respectively (Table 5)

Table 6 Univariable analysis by $\lambda 2$ test of the factors associated with $T$. trichuria infection in tea garden community of Sylhet

\begin{tabular}{|c|c|c|c|}
\hline Characteristics & $\begin{array}{l}\text { Positive } \\
n=42(\%)\end{array}$ & $\begin{array}{l}\text { Negative } \\
n=258(\%)\end{array}$ & P-value \\
\hline \multicolumn{4}{|l|}{ Season } \\
\hline Rainy & $16(69.23)$ & $49(30.77)$ & \\
\hline Winter & $20(26.05)$ & $96(73.95)$ & \\
\hline Summer & $06(42.40)$ & $113(57.76)$ & $<0.01 * * *$ \\
\hline \multicolumn{4}{|l|}{ Areas } \\
\hline Khadim tea estate & $14(63.83)$ & $33(36.17)$ & \\
\hline Burjan tea estate & $18(55.70)$ & $61(44.30)$ & \\
\hline Lakkatora tea estate & $02(29.23)$ & $63(70.77)$ & \\
\hline Malnichara tea esstate & $08(39.68)$ & $55(60.32)$ & \\
\hline Daldali tea estate & 0 & $46(84.78)$ & $<0.01 * * *$ \\
\hline \multicolumn{4}{|c|}{ Participant's schooling } \\
\hline Primary & $22(50.96)$ & $82(49.04)$ & \\
\hline Secondary & $03(18.75)$ & $13(81.25)$ & \\
\hline No schooling & $17(38.33)$ & $163(61.67)$ & 0.02 \\
\hline \multicolumn{4}{|l|}{ Father's occupation } \\
\hline Unemployed & $03(63.64)$ & $08(36.36)$ & \\
\hline Day labourer & $24(46.70)$ & $158(53.30)$ & \\
\hline Service & II (28.75) & 69(7I.25) & \\
\hline Tea garden worker & $02(33.33)$ & $07(66.67)$ & \\
\hline Other & $02(38.89)$ & $16(61.11)$ & 0.67 \\
\hline \multicolumn{4}{|c|}{ Monthly family income (Taka/Month) } \\
\hline$\leq 5000$ & $2 I(50.49)$ & $82(49.51)$ & \\
\hline$>5000$ & $21(37.06)$ & $176(62.94)$ & 0.02 \\
\hline \multicolumn{4}{|l|}{ Receive treatment } \\
\hline No & $24(65.60)$ & $101(34.40)$ & \\
\hline
\end{tabular}

$\begin{array}{llll}\text { Yes } & \text { |8(24.57) } & \text { |57(75.43) } & 0.03\end{array}$

Treatment 4 month interval

$\begin{array}{lll}\text { No } & 33(62.29) \quad \text { |42(37.7I) }\end{array}$

Yes $\quad 09(12.80) \quad 116(87.20) \quad 0.04$

\section{Toilet floor}

$\begin{array}{llll}\text { Mud } & 26(58.59) & 175(41.4 I) & \\ \text { Bamboo } & 16(33.33) & 83(66.67) & 0.45\end{array}$

Where dispose stool

Around house $\quad 21(34.12) \quad 190(65.88)$

$\begin{array}{llll}\text { Jungle/Tea garden } & 2 \mathrm{I}(59.55) & 68(40.45) & 0.02\end{array}$

Rub hand after toilet

No $\quad 35(39.84) \quad 221(60.16)$

$\begin{array}{llll}\text { Yes } & 07(52.27) & 37(47.73) & 0.69\end{array}$

Use disinfectant toilet cleaning

No 13(56.76) 6I(43.24)

$\begin{array}{lll}\text { Yes } & \text { 29(36.73) } & \text { 197(63.27) }\end{array}$

Have foot ware

$\begin{array}{llll}\text { No } & 02(04.76) & 05(01.94) & \\ \text { Yes } & 40(95.24) & 253(98.06) & 0.26 \\ \text { Use shoe inside home } & & & \\ \text { Always } & 04(09.52) & 24(09.30) & \\ \text { Most time } & \mathrm{II}(26.19) & \mathrm{II}(45.35) & \\ \text { Rarely } & 25(59.52) & \mathrm{II} 2(43.4 \mathrm{I}) & \\ \text { Never } & 0 \mathrm{I}(02.38) & 04(01.55) & \\ \text { Not applicable } & 0 \mathrm{I}(02.38) & 01(0.04) & 0.17\end{array}$

Activity outside home

$\begin{array}{llll}\text { Always } & 07(16.67) & 37(14.34) & \\ \text { Most time } & 14(33.33) & 147(56.98) & \\ \text { Rarely } & 20(47.62) & 71(27.52) & \\ \text { Never } & 00(0.00) & 02(0.07) & \\ \text { Not applicable } & 0 I(02.38) & 0 I(0.04) & <0.01 * * * \\ \text { Work in bare foot } & & & \\ \text { No } & 09(21.43) & 46(17.83) & \\ \text { yes } & 33(78.57) & 2 \mid 2(82.17) & 0.58\end{array}$

Wash feet coming from out

\begin{tabular}{llll} 
Not always & $23(54.76)$ & $149(57.75)$ & \\
Always & $19(45.24)$ & $109(42.25)$ & 0.72 \\
\hline
\end{tabular}

$* \mathrm{P}<0.05$ Significant association with positive sample, $* * *=$ highly significant 
Table 7 Multi-variable logistic regression analysis of Trichuris trichiura infection in Tea garden community of Sylhet

\begin{tabular}{|c|c|c|}
\hline Name of variable & Odds ratio ( $95 \%$ confidence Intervals) & P-value \\
\hline \multicolumn{3}{|l|}{ Season } \\
\hline Rainy & $6.15(2.27-16.66)$ & $<0.01 * * *$ \\
\hline Winter & $3.92(1.51-10.17)$ & \\
\hline Summer & 1 & \\
\hline \multicolumn{3}{|l|}{ Areas } \\
\hline Khadim tea estate & $2.92(1.11-7.69)$ & \\
\hline Burjan tea estate & $2.03(0.82-5.04)$ & 0.03 \\
\hline Lakkatora tea estate & $0.22(0.04-1.07)$ & \\
\hline Malnichara tea estate & $0.15(0.07-.03)$ & \\
\hline Daldali tea estate & I & \\
\hline Income (Taka/Month) & $2.15(1.11-4.15)$ & \\
\hline$\leq 5000$ & 1 & 0.02 \\
\hline \multicolumn{3}{|l|}{$>5000$} \\
\hline \multicolumn{3}{|l|}{ Receive anthelmintic } \\
\hline No & $2.07(1.07-4.01)$ & 0.03 \\
\hline Yes & 1 & \\
\hline \multicolumn{3}{|c|}{ Receive anthelmintic 4 month interval } \\
\hline No & $2.99(\mid .38-6.5 I)$ & 0.01 \\
\hline Yes & I & \\
\hline \multicolumn{3}{|l|}{ Disposal of stool } \\
\hline Jungle/garden & $2.79(1.44-5.43)$ & 0.02 \\
\hline Around house & 1 & \\
\hline
\end{tabular}

$* \mathrm{P}<0.05$ Significant association with positive sample, $* * *=$ highly significant

\section{Discussion}

This cross sectional study included 300 participants in rural slum of tea garden community in Sylhet district. These numbers of participants are representative of the local population in this poor remote setting as previous study. ${ }^{16}$ The overall prevalence of $T$. trichiura infection was $14.00 \%$ (95\% CI 10.28-18.45). This finding was higher than the reports from other study of Bangladesh., ${ }^{7,16}$ The variation of prevalence of $T$. trichiura infection in different studies would be due to differences in climate and geographical location of the areas. What's more, socio-economic condition as well as environmental, household, personal hygiene plays a pivotal role for the variation in the prevalence of infection. ${ }^{17}$ There is a paucity of information in the prevalence of T. trichiura because at the best of my knowledge this is the first time reporting the age category. Previous study targeted the overall infection of the regular female tea pluckers. ${ }^{16}$ Prevalence of Trichuris infection in the slums of urban areas was $03.43 \%$ which is lower than the rural slum areas $31.58 \%$ (95\% CI 12.58-56.55). Exposure of older children to the infection is higher as they show different way of behaviors. However, older children accumulate infection during their lifetime. ${ }^{18}$ The existence of this parasite higher among the children might be due to the resistant nature of the eggs against different environmental factors. ${ }^{19}$ Trichuris infection is higher in older children which was consistent to other researchers..$^{20,21}$ Trichuris infection is comparatively higher in male than female which is contradictory to $0^{7,18}$ but similar to. ${ }^{22}$

It is known that a single Kao Katz thick smear done on a single sample has a relatively lower sensitivity. ${ }^{23}$ Therefore it could be assumed that the true prevalence of infection is higher than which documented here. In addition the Kato Katz technique does not allow detection of a broader range of parasite species.

In this study the infection intensity of $T$. trichiura measured as an indirect tool of morbidity. T. trichiura infection was identified as light, moderate and heavy infection but in study of ${ }^{18}$ only light and moderate infection found. However, there was prevalence of malnutrition and anemia in the study subjects but no association with the Trichuris infection although T. trichiura were associated with higher level of anemia. ${ }^{24}$ 
Determinants analysis showed that the areas were significantly associated with $T$. trichiura infection which is similar to the findings of. ${ }^{22}$ This might be due to the climatic condition like humid and warm weather, poor hygiene of the rural slum, lack of provision for potable water.

In the multivariate analysis, T. trichiura is best predicted by season. Rainy season contributed significantly the infection because children spend more time outside of the house and eat frequently unwashed fruit from the gardens. $\mathrm{OR}=6.15(95 \%$ CI $2.27-16.66 ; \mathrm{P}=<0.01)$ than winter $\mathrm{OR}=3.92(95 \%$ CI $1.51-10.17 ; \mathrm{P}=<0.01)$. This study is slight contradictory by the Matthys B \& Gungoren B et al. ${ }^{25,26}$ that speculated parasitic infection might be higher in summer.

We identified periodic anthelmintic taking reduces the parasitic infection significantly. The participants who does not take anthelmintic four month interval they had opportunity of getting infection $\mathrm{OR}=2.99(95 \%$ CI $1.38-6.51 ; \mathrm{P}<0.01)$. Unhygienic disposal of human stool significantly associated with Trichuris infection because disposal of stool in jungle or tea garden canal showed $\mathrm{OR}=2.79(95 \%$ CI 1.44 5.43; $\mathrm{P}<0.02$ ), where children and workers regularly enter in stool conveying canal which ultimately promotes the transmission cycle (Figure 3$).{ }^{27}$

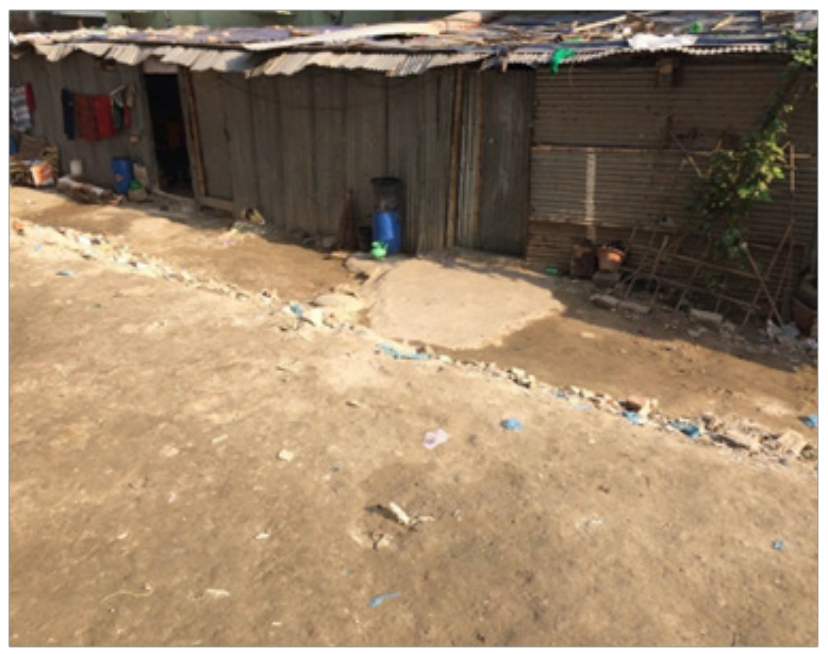

Figure 3 House yard of rural tea garden community of Sylhet, Bangladesh, early 2014.

The economic condition of the household is significantly associated with T. trichiura infection because with low family income the rate of infection increases as we found in our study 2.15 (95\% CI 1.11-4.15; $\mathrm{P}<0.02$ ) which is similar to the findings of ${ }^{28}$ when the family income increases then they had privileges to maintain all hygienic measures.

Factors like education, occupation, toilet floor and work in bare foot did not correlate with T. trichiura infection which seems to have an association with infection. Steenhard NR et al. ${ }^{22}$ reported illiterate mother is significantly associated with infection.

Chemotherapy on regular basis for prevention has been shown to reduce parasitic infection in a cost effective way. ${ }^{29,30}$ Hygienic practices needed additionally to ensure a long term benefits. ${ }^{31}$ To keep the children free from parasite for longer period, treatment should be started in early life. The ahead challenges is how best we can reach to the tea garden communities and identify innovative approaches for delivery of anthelmintic to the vulnerable age groups.

\section{Study limitations}

Financial constraints made it difficult to check for false negatives using a more sensitive method like formal-ether concentration technique as it is known that Kato- Katz technique tends to have low sensitivity in the diagnosis of intestinal helminths particularly in areas with high proportions of low intensity of infections. ${ }^{31,32}$ Therefore, there could be some false negative, thus underestimating the prevalence.

\section{Conclusion}

T. trichiura infection is prevalent both in the children and adult. The determinants of the infections suggest proper disposal of human stool, anthelmintic taking four month intervals in the slum rural areas to reduce the worms' burden in the community.

\section{Acknowledgements}

The Authors thankful to International Center for Diarrhoeal Disease Research Bangladesh (icddr'b), Dhaka, Bangladesh for their logistic supports and providing laboratory facilities. We also thank the Department of Parasitology, Sylhet Agricultural University, Sylhet. We also acknowledge the contribution of the study participants.

\section{Conflict of interest}

There is no conflict to publish the article in this Journal.

\section{References}

1. Tadesse G. The prevalence of intestinal helminthic infections and associated risk factors among school children in Babile town, eastern Ethiopia. Ethiopian Journal of Health Development. 2005;19(2):140-147.

2. Ogbe MG, Edet E, Isichel M. Intestinal helminth infection in primary school children in areas of operation of Shell Petroleum Development Company of Nigeria (SPDC), Western Division in Delta State. Nigerian Journal of Parasitology. 2006;23(1):3-10. 
3. Chan MS. The global burden of intestinal nematode infections-fifty years on. Parasitol today. 1997;13(11):438-443.

4. Committee WE. Prevention and control of schistosomiasis and soiltransmitted helminthiasis. WHO technical report series. 2002;912:57.

5. Cairncross S, Bartram J, Cumming O, et al. Hygiene, sanitation, and water: what needs to be done? PLoS medicine. 2010;7(11):1366.

6. Bethony J, Brooker S, Albonico M, et al. Soil-transmitted helminth infections: ascariasis, trichuriasis, and hookworm. Lancet. 2006;367(9521):1521-1532.

7. Khanum H, Rahman F, Zaman RF. Occurrence of intestinal parasites among the teachers, students and staffs of Dhaka University. Journal of the Asiatic Society of Bangladesh, Science. 2014;39(2):239-246.

8. Ali S. Incidence of hookworm among the workers in tea garden Bangladesh Medical Research Council Bulletin. 1985;11(2):69-74.

9. Hotez PJ, Brindley PJ, Bethony JM, et al. Helminth infections: the great neglected tropical diseases. J Clin Invest. 2008;118(118 (4):1311-1321.

10. Wang X, Zhang L, Luo R, et al. Soil-transmitted helminth infections and correlated risk factors in preschool and school-aged children in rural southwest China. PLoS One. 2012;7(9):e45939.

11. WHO. Soil-transmitted helminthiases: number of children treated in 2012. WHO Weekly Epidemiological Record No, 2014. 13: p. 89

12. www.banglapedia.org/HT/S_0739.htm

13. Islam S. Banglapedia: national encyclopedia of Bangladesh/chief editor, Sirajul Islam; managing editor, Sajahan Miah. Asiatic society of Bangladesh; 2003.

14. Katz N, Chaves A, Pellegrino JA. A simple device for quantitative stool thick-smear technique in schistosomiasis mansoni. Rev Inst Med Trop Sao Paulo. 1972;14(6):397-400.

15. WHO. Cellophane faecal thick smear examination technique (Kato) for diagnosis of intestinal schistosomiasis and gastrointestinal helminth infections. PDP/83.3, WHO, Geneva: 1983.

16. Gilgen DD, Mascie-Taylor CG, Rosetta LL. Intestinal helminth infections, anaemia and labour productivity of female tea pluckers in Bangladesh. Trop Med Int Health. 2001;6(6):449-457.

17. Sultana Y, Gilbert GL, Ahmed BN, et al. Strongyloidiasis in a high risk community of Dhaka, Bangladesh. Trans $R$ Soc Trop Med Hyg. 2012;106(12):756-762.

18. Kounnavong S, Vonglokham M, Houamboun K, et al. Soil-transmitted helminth infections and risk factors in preschool children in southern rural Lao People's Democratic Republic. Trans R Soc Trop Med Hyg. 2011;105(3):160-166

19. Amare B, Ali J, Moges B, et al. Nutritional status, intestinal parasite infection and allergy among school children in Northwest Ethiopia. BMC pediatr. 2013;13(1):7.
20. Escobedo AA, Cañete R, Núñez FA. Prevalence, risk factors and clinical features associated with intestinal parasitic infections in children from San Juan y Martínez, Pinar del Río, Cuba. West Indian Med J. 2008;57(4):378-382.

21. Michael E. This wormy world: Fifty years on. The challenge of controlling common helminthiases of humans today. Parasit Today. 1997;13(11):407-408

22. Steenhard NR, Ørnbjerg N, Mølbak K. Concurrent infections and socioeconomic determinants of geohelminth infection: a community study of schoolchildren in periurban Guinea-Bissau. Trans $R$ Soc Trop Med H. 2009;103(8):839-845.

23. Tarafder MR, Carabin H, Joseph L, et al. Estimating the sensitivity and specificity of Kato-Katz stool examination technique for detection of hookworms, Ascaris lumbricoides and Trichuris trichiura infections in humans in the absence of a 'gold standard'. Int $J$ Parasitol. 2010;40(4):399-404.

24. Ezeamama AE, McGarvey ST, Acosta LP, et al. The synergistic effect of concomitant schistosomiasis, hookworm, and trichuris infections on children's anemia burden. PLoS Negl Trop Dis. 2008;2(6):e245.

25. Matthys B, Bobieva M, Karimova G, et al. Prevalence and risk factors of helminths and intestinal protozoa infections among children from primary schools in western Tajikistan. Parasit Vectors. 2011;4(1):195.

26. Gungoren B. Effect of hygiene promotion on the risk of reinfection rate of intestinal parasites in children in rural Uzbekistan. Transactions of the Royal Society of Tropical Medicine and Hygiene. 2007;101(6):564-569.

27. Zheng Q, Ying C, Hao-Bing z, et al. The control of hookworm infection in China. Parasit Vectors. 2009;2(1):44.

28. Ngui R, Ishak S, Chuen CS, et al. Prevalence and risk factors of intestinal parasitism in rural and remote West Malaysia. PLoS Negl Trop Dis. 2011;5(3):e974.

29. Phommasack B, Saklokham K, Chanthavisouk C, et al. Coverage and costs of a school deworming programme in 2007 targeting all primary schools in Lao PDR. Trans R Soc Trop Med Hyg.2008;102(12):1201-1206.

30. Kojima S, Yoshiki A, Nobuo O, et al. School-health-based parasite control initiatives: extending successful Japanese policies to Asia and Africa. Trends in parasitology. 2007;23(2):54-57.

31. Knopp S, Mgeni AF, Khamis IS, et al. Diagnosis of soil-transmitted helminths in the era of preventive chemotherapy: effect of multiple stool sampling and use of different diagnostic techniques. PLoS Negl Trop Dis. 2008;2(11):e331.

32. Hossain M. et al. Prevalence and determinants of trichuris trichiura infection in tea garden community of sylhet, Bangladesh. $21^{\text {th }}$ BSVER Annual Scientific Conference, BAU, Bangladesh, 2016; 63. 